\title{
Managing Perceived Coping Behavior While Mentoring Doctoral Students
}

\author{
Robert E. Samuel \\ Widener University, \\ Chester, PA, USA
}

Robert.Samuel@ieee.org

\author{
Frederick G. Kohun \\ Robert Morris University, \\ Pittsburgh, PA, USA
}

kohun@rmu.edu

\begin{abstract}
This exploratory research study examined the perceived behaviors of doctoral students by faculty member mentors through a concurrent triangulation design using quantitative survey and ethnography observational methods. Through the perspective of Kirton's Adaption-Innovation theory, a doctoral cohort class was observed over the length of their studies. The cohort's faculty members, acting as mentors, hypothesized that some student's behavioral attitude changed from the initial course to the final stages of dissertation submission. This study shows that some doctoral students exhibited coping behaviors that indicated a perceived behavioral shift. Through the awareness of these behaviors, faculty members could develop techniques to help manage the mentor and mentee relationship.
\end{abstract}

Keywords: Doctoral Mentoring, Coping Behavior, KAI, Cognitive Style, Doctoral Program

\section{Introduction and Background}

A recent study from Protivnak and Foss (2009) found that a few doctoral students listed their motivation to achieve a doctoral degree as a means to manage the stress and cope. Additionally, Protivnak and Foss discovered that collaboration between students and faculty members was an important factor for successful completion of doctoral studies. They reported that many students felt "mentoring to be the most helpful experience in their doctoral studies" (p. 246); however, some students had difficulty with doctoral mentoring and felt abandoned (Protivnak \& Foss, 2009). Supportive classmates who provided encouragement and guidance were an important aspect for doctoral students to help address stressful situations (Protivnak \& Foss, 2009). Ali and Kohun (2006) reviewed the topic of isolation feelings and the counter measures deployed to minimize isolation, demonstrating that isolation could be a factor in influencing one's behavior.

For this research study, increased tension was observed during the dissertation creation process between advisors, acting as a mentor, with some students. Mentors and mentees prefer relation-

Material published as part of this publication, either on-line or in print, is copyrighted by the Informing Science Institute. Permission to make digital or paper copy of part or all of these works for personal or classroom use is granted without fee provided that the copies are not made or distributed for profit or commercial advantage AND that copies 1) bear this notice in full and 2) give the full citation on the first page. It is permissible to abstract these works so long as credit is given. To copy in all other cases or to republish or to post on a server or to redistribute to lists requires specific permission and payment of a fee. Contact 0HPublisher@InformingScience.org to request redistribution permission. ships that provide a positive camaraderie, but more importantly, a relationship where common goals are more easily achievable provides more weight (Ugrin, Odom, \& Pearson, 2008). Urgin, et al. (2008) researched leader member exchange, the social exchange quality in relationships, during mentoring along with demographics of gender and ethnicity. They discovered that their qualitative follow-up interviews sup- 
ported their quantitative results that "faculty members indicated that they prefer working with people that have personality traits that they like" (p. 348) even more than the variables of demographics. The authors recommend further exploration of these complex factors.

Hall and Burns (2009) reviewed the role of mentoring by faculty members through the lens of identity theory. From the fluid sociocultural and anthropological view of identity, the authors posit that doctoral students create new identities as well as evaluate themselves under a new researcher framework during the doctoral program. This transformation creates perceived coping behavior impressions as high-valued professionals are often shifted to a position where their role has lower value. Lazarus and Folkman (1984) defined coping as the "constantly changing cognitive and behavioral efforts to manage specific external and/or internal demands that are appraised as taxing or exceeding the resources of the person" (p. 141). As doctoral students redefine their identity, Hall and Burns (2009) stated, "students who question valued identities or seek to develop identities that do not fit the status quo may find themselves excluded" (p. 60). Therefore, the role of mentoring doctoral students must include managing the student's identity formation to develop cultural awareness of the program and faculty members.

Terry, DeMichiell, and Williams (2009) discussed five issues of the mentor/mentee relationship including a) mentoring requirements, b) compatibility of scholarly work, c) personality compatibility, d) presentation/publication opportunities, as well as e) time and schedule for interaction. Within the review of the personality compatibility issue, the authors discuss the importance of the compatible thinking styles between two persons to maximize the efficiency of process and adherence to deadlines. Terry et al. (2009) cited that "personality factors do enter in the equation of collaboration and unconsciously, either or both of the workers should consider this aspect before commitment of any major effort" (p.10). This study researched the similarity or difference of thinking styles in terms of cognitive styles.

\section{The Research Model}

The faculty members of Robert Morris University's Doctoral program in Information Systems and Communication often observed doctoral student's behavioral shifts during the lifecycle of the doctoral program. Sometimes these behaviors manifested into conflict between cohort individuals and faculty members during the timeline of the doctoral program. Doctoral advisors, acting as mentors, were seeking techniques to aid their efforts in effectively mentoring students during a doctoral program and the dissertation process. This research study examined students' coping behavior and students' cognitive style with respect to the program's cognitive climate. This exploratory study included a concurrent triangulation design with a quantitative survey method (Kirton's Adaption-Innovation Inventory) and an ethnography observational method (Creswell, 2003; Denzin \& Lincoln, 2008, Trochim \& Donnelly, 2007). With respect to the student's view, this study focused on two research questions:

1) - What aspects of a student's cognitive style result in perceived coping behavior as observed?

2) - How does perceived coping behavior manifest within the environment and culture of a doctoral program?

The research model is represented in Figure 1. 


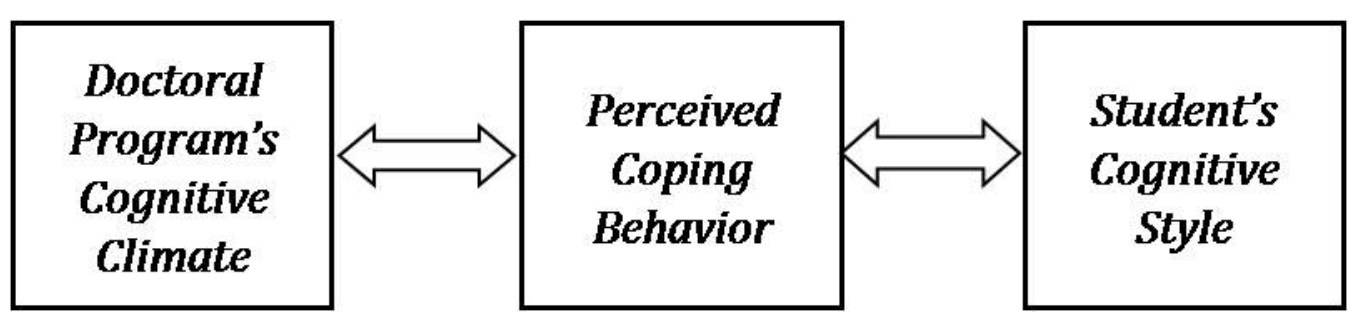

Figure 1. Research Model

\section{Cognitive Style}

Cognitive style is defined as "the strategic, stable characteristic - the preferred way in which people respond to and seek to bring about change" (Kirton, 2003, p. 43). Cognitive style is the preferred approach or manner in which an individual addresses problem solving. According to Kirton's Adaption-Innovation (KAI) theory (2003), cognitive style can be measured on a continuum between more adaptive and more innovative. In general, there is no ideal style; instead any style provides different advantages and disadvantages with respect to a particular problem. Adaptors will have a tendency to be precise and methodical in their approach. They prefer to solve problems by following guidelines and rules as well as produce a few relevant and safe ideas. An innovator will have a tendency to look at problems from different angles that could be viewed as undisciplined or inefficient. Innovators often challenge established rules and processes to produce many ideas that include some that might be unproven (Kirton, 2003).

Kirton (2003) introduced his KAI Inventory in 1976 to measure cognitive styles. This cognitive style inventory is a quantitative measure and fits appropriately to the research design by facilitating the collection of key personality traits related to academic problem solving (Kirton, 2003). As a psychometric instrument, the KAI inventory has been validated in numerous studies and found to be reliable across multiple fields of research (Kirton, 1999). The KAI Inventory provides an overall total score based on the summation of three trait factors that reflect Sufficiency of Originality, Efficiency, and Rule and Group Conformity (Kirton, 2003). The Sufficiency of Originality (SO) factor generally indicates differences in people regarding their preference of original notions or ideas. Efficiency (E) shows the style difference on the preferred method of problem solving. Rule and Group Conformity (R/G) shows the style difference of managing structure within which problem solving occurs (2003).

KAI requires respondents to personally reflect and estimate how easy or difficult it is to sustain a particular behavior over a long period of time using a 32-item, Likert-type, self-reporting instrument. Respondents select their item choice on a 17 dot continuum across the four descriptors ranging "Very Hard" to "Hard" to "Easy" to "Very Easy". Each response is then associated with a score ranging from 1 to 5 for each item. Each item is associated with one trait factor (SO, E, or $\mathrm{R} / \mathrm{G})$. The measure is scored from a very high adaptive score of 32 to a highly innovative score of 160 with a theoretical mean of 96 (Kirton, 2003). From these trait factors and total score, the participants are grouped based a continuum from a label of high adaptors to high innovators. The general population follows a normal distribution over this continuum (Kirton, 1999; 2003).

The SO trait factor measures how different individuals contribute original ideas or concepts. Kirton (1999) explains this is similar to Rogers' (1959) concept of the "creative loner" along the innovator pole. The E trait factor measures the level of detail and thoroughness for problem solving. Kirton (1999) parallels this to Weber's (1970) analysis of precision, reliability, and efficiency. The R/G trait factor measures one's preference for operating within the rules and guidelines to approach problem solving. Kirton (1999) relates this to Merton's (1957) analysis of bureaucratic structure to be methodical and attain a degree of conformity. 


\section{Methodology and Results}

The KAI Inventory was administered to doctoral students $(\mathrm{n}=12)$ during the first semester of coursework and then again during the final year of dissertation creation (post comprehensive examination as well as dissertation proposal approval). The cognitive style data of each of the student participants was analyzed using SPSS Statistics version 17.0 for the mean and standard deviation for the total as well as each sub-score for both inventory versions of the pilot sample. The empirical total score group mean became more adaptive with a 1.92-point mean shift from 101.25 in the first year to 99.33 in the last year (see Table 1). The standard deviation increased from 17.01 to 23.41 respectively. The female students sample demonstrated a 2.0-point total score mean shift towards a more adaptive style (from 102.25 during the first year to 100.25 during the last year) with a standard deviation increase from 7.81 to 13.55 from first to last year. The male student sample demonstrated a 1.87-point total score mean shift from 100.75 during the first year to 98.88 during the last year. The standard deviation also increased from 20.69 the first year to 27.96 during last year. See Figures 2 and 3 for frequency distribution of the first year and the last year respectively. When reviewing the trait factors $(\mathrm{SO}, \mathrm{E}, \mathrm{R} / \mathrm{G})$ from the first year to the last year, SO scores became more innovative while the scores for both $\mathrm{E}$ and R/G became more adaptive. The general population mean of SO is 41 . Therefore, the group cognitive climate (regardless of gender demographics) for idea generation inclusive of the first and last year for this cohort is more innovative than the population. The general population mean of $\mathrm{E}$ is 19 . Therefore, the cognitive climate efficiency for this cohort is significantly more adaptive, especially in the last year. The general population mean of $\mathrm{R} / \mathrm{G}$ is 35 . Therefore, the cognitive climate of this cohort is relatively similar to the population with a more adaptive shift from the first year to the last year.

Table 1 KAI Scores of Doctoral Students.

\begin{tabular}{|c|c|c|c|c|c|c|c|c|c|}
\hline \multicolumn{2}{|c|}{ Student Gender } & $\begin{array}{c}\text { First Year } \\
\text { Total }\end{array}$ & $\begin{array}{c}\text { Last Year } \\
\text { Total }\end{array}$ & $\begin{array}{c}\text { First Year } \\
\text { so }\end{array}$ & $\begin{array}{l}\text { Last Year } \\
\text { SO }\end{array}$ & $\begin{array}{c}\text { First Year } \\
\text { E }\end{array}$ & $\begin{array}{c}\text { Last Year } \\
\text { E }\end{array}$ & $\begin{array}{c}\text { First Year } \\
\text { R }\end{array}$ & $\begin{array}{c}\text { Last Year } \\
\mathrm{R}\end{array}$ \\
\hline \multirow[t]{5}{*}{ Female } & Mean & 102.25 & 100.25 & 50.00 & 50.50 & 16.50 & 13.75 & 35.75 & 37.00 \\
\hline & $\mathrm{N}$ & 4 & 4 & 4 & 4 & 4 & 4 & 4 & 4 \\
\hline & Std. Deviation & 7.805 & 13.549 & 7.439 & 9.747 & 3.109 & 7.320 & 5.058 & 4.320 \\
\hline & Minimum & 95 & 85 & 39 & 36 & 14 & 8 & 30 & 33 \\
\hline & Maximum & 109 & 118 & 55 & 57 & 21 & 24 & 40 & 43 \\
\hline \multirow[t]{5}{*}{ Male } & Mean & 100.75 & 98.88 & 46.88 & 48.88 & 17.75 & 16.88 & 36.12 & 33.13 \\
\hline & $\mathrm{N}$ & 8 & 8 & 8 & 8 & 8 & 8 & 8 & 8 \\
\hline & Std. Deviation & 20.686 & 27.956 & 10.218 & 11.946 & 5.497 & 7.120 & 8.643 & 11.141 \\
\hline & Minimum & 56 & 45 & 25 & 23 & 11 & 8 & 20 & 14 \\
\hline & Maximum & 121 & 139 & 60 & 62 & 26 & 29 & 46 & 48 \\
\hline \multirow[t]{5}{*}{ Total } & Mean & 101.25 & 99.33 & 47.92 & 49.42 & 17.33 & 15.83 & 36.00 & 34.42 \\
\hline & $\mathrm{N}$ & 12 & 12 & 12 & 12 & 12 & 12 & 12 & 12 \\
\hline & Std. Deviation & 17.014 & 23.407 & 9.160 & 10.833 & 4.716 & 7.017 & 7.385 & 9.366 \\
\hline & Minimum & 56 & 45 & 25 & 23 & 11 & 8 & 20 & 14 \\
\hline & Maximum & 121 & 139 & 60 & 62 & 26 & 29 & 46 & 48 \\
\hline
\end{tabular}




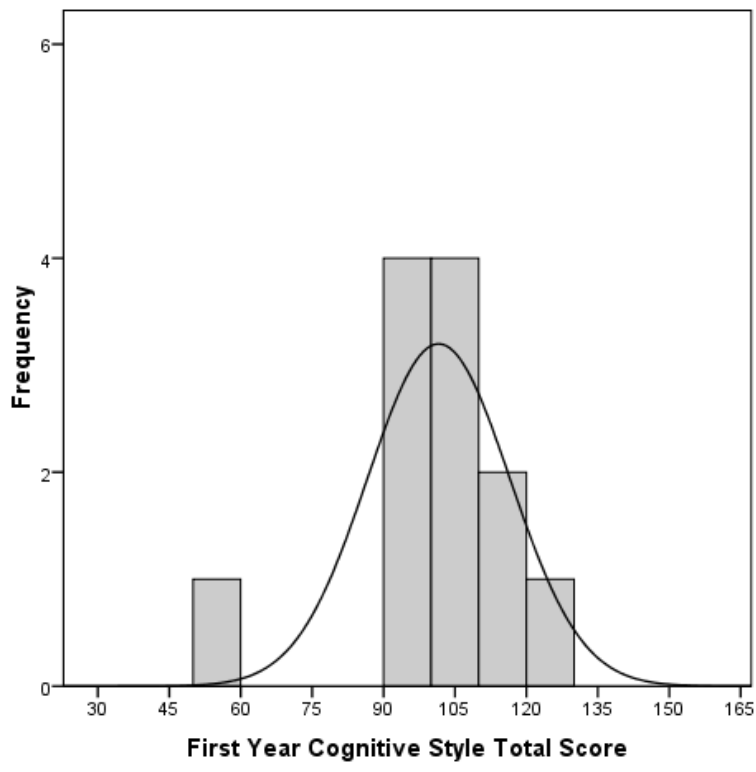
Mean $=101.25$
Std. Dev. $=17.014$
$N=12$

Figure 2. KAI Frequency Distribution during First Year

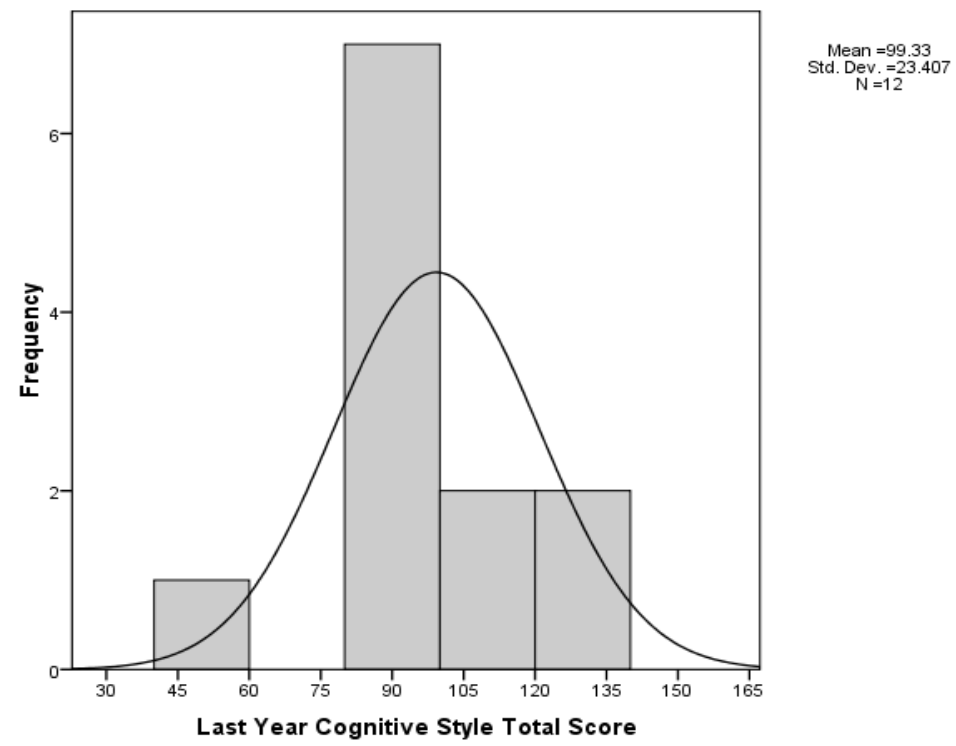

Figure 3. KAI Frequency Distribution during Last Year

\section{Discussion}

Geisler, Wiedig-Allison, and Weber (2009) discovered that layperson-observed personality impressions of interpersonal attraction and social functioning could be inferred from observing individuals exhibiting coping behavior with respect to stress as well as adversity. Therefore, they empirically confirmed their "assumption that coping behavior is diagnostic of personality in a way that mirrors the associations between personality and coping documented in the literature" (Geisler et al., 2009, p. 301). Kirton (2003) concluded that some coping behavior is always required 
and interprets coping behavior as everyone's ability to address current problems in their nonpreferred way along the two axes of intensity as well as duration. Kirton (2003) suggested that the rise is not linear over extended time but is exponential in nature with respect to effort (see Figure 4). Increased coping behavior can also be contributed to the difference in cognitive style scores between students and faculty mentors as well as the overall group cognitive climate, such as a cohort in a doctoral program (Kirton, 2003).

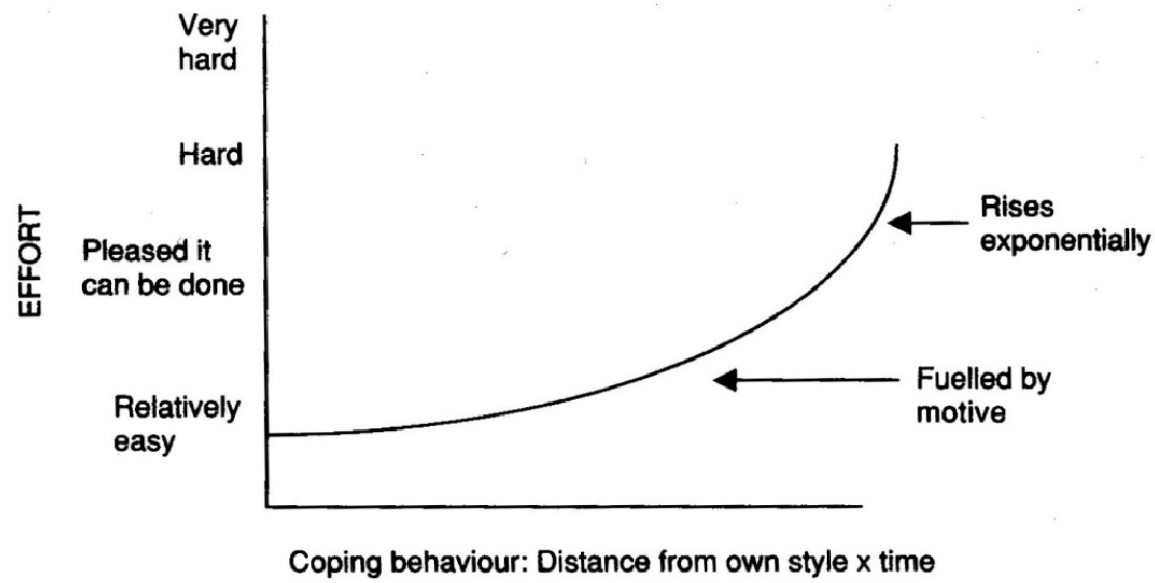

Figure 4. Coping Behavior Schema (Kirton, 2003) - Used with Permission

Kirton (2003) argued that all individuals face coping behaviors. Individuals find comfort in solving problems that are similar in nature to their preferred cognitive style. However, a wide cognitive style range is necessary to solve most complex problems. When an individual is forced to solved problems outside their preferred cognitive style, coping behavior is needed to handle the resulting stress (Kirton, 2003). Coping behavior can be an expensive cost for individuals. Motive balances the checkbook of coping by providing additional energy and minimizing discomfort until the task is complete. Often, a small amount of coping behavior is barely noticed. However, increased coping over long periods is likely to raise anxiety (Kirton, 2003). Doctoral programs require an emotional aspect from students to address a wide range of problems that require some level of coping behavior (Ali \& Kohun 2006). Over time, the perceived coping behavior exhibited by the students could manifest into tension as well as conflict in the mentor (faculty advisor) and mentee (student) relationship.

Self-efficacy is the "belief in one's capabilities to organize and execute the courses of action required to produce given attainments" (Bandura, 1997, p. 2) and to "mobilize the motivation, cognitive resources, and courses of action needed to exercise control over events" (Wood \& Bandura, 1989 , p. 364). Such beliefs have an influence on an individual's level of effort and preservation as well as resilience in the face of difficult, goal attainment and stress perceptions (Bandura, 2001). Lev and Koslowsky (2008) explored the impact of this concept on teacher's work that could impact student performance. Self-efficacy could be a contributing construct that impacts a student's perceived coping behavior.

With respect to the two research questions addressed in this study, while Kirton's $(1999,2003)$ work over time has shown that his identified cognitive styles do not change much over the course of an individual's lifetime, this study has shown that reported cognitive styles can and do change when faced with situational events. The changes observed over time can most likely be attributed to coping behavior (that potential is influenced by self-efficacy) - at least in the confines of this 
particular doctoral program. The doctoral program, for the most part, pushes students into a discomfort zone. The "discomfort zone" consists of cultural changes in power relationship expectations and academic accountability. The discomfort zone manifests itself in the study as a change in the KAI measure. This seems to indicate that, at least for the duration of this doctoral program, this is a life changing process going on as reflected in the KAI cognitive style measure. It can be argued, in Kirton's context, that these changes are coping mechanisms. For some students increased innovation or "creativity" had been initiated as a coping behavior. For others, coping in the form of the other extreme - greater detail, reduced scope, narrowed and focused microanalysis - doing as they would have done except better and in an extremely narrow context.

Doctoral faculty members, once generally aware of a doctoral student's cognitive style, can direct their doctoral mentoring efforts to anticipate student coping mechanisms. Those students that are innovative can be monitored to be more focused, while the adaptive students can likewise be monitored to direct their coping tendencies to "open" up to new and different ideas. Doctoral faculty members can also use the student's KAI score to adapt their teaching and doctoral mentoring styles to enhance personal communication as well as a tool to foster greater impact on the student's lives.

\section{Conclusion}

The culture of the doctoral program brings strongly motivated individuals together working towards a common goal. However, these goals are only achievable based on individual efforts of the students. An identity transformation develops as students become subject matter experts regarding their dissertation that results in a reversal of roles where the faculty member learns from their students. Additionally, students are slowly transitioning, mostly subconsciously, from a job perspective to a career perspective. Students become aware of multiple behavioral constructs, such as cognitive style, coping behavior, and self-efficacy, while increasing their own intellectual knowledge. A future longitudinal study with a larger sample could help determine more granular constructs for mentors to specifically manage to minimize coping behaviors. Further research will also be directed to see if these cognitive style changes are, in fact, temporary coping mechanisms or are permanent life changes.

\section{References}

Ali, A. \& Kohun, F. (2006). Dealing with isolation feelings in IS doctoral programs. International Journal of Doctoral Studies, 1, 21- 33. Retreived from http://www.ijds.org/Volume1/IJDSv1p021033Ali13.pdf

Bandura, A. (1997). Self-efficacy: The exercise of control. New York: Freeman.

Bandura, A. (2001). Social cognitive theory: An agentic perspective. Annual Review of Psychology, 52, 1 26.

Creswell, J. W. (2003). Research design: Qualitative, quantitative, and mixed methods approaches (2nd ed.). Thousand Oaks, CA: Sage.

Denzin, N. K., \& Lincoln, Y. S. (2008). Collecting and interpreting qualitative materials. Thousand Oaks, CA: Sage.

Geisler, F. C., Wiedig-Allison, M., \& Weber, H. (2009). What coping tells about personality. European Journal of Personality, 23, 289-306.

Hall, L. A., \& Burns, L. D. (2009). Identity development and mentoring in doctoral education. Harvard Educational Review, 79(1), $49-70$.

Kirton, M. J. (1999). Kirton adaption-innovation inventory manual (3rd ed.). Suffolk, U.K: Occupational Research Centre, Newmarket. 
Kirton, M. J. (2003). Adaption-innovation: In the context of diversity and change. Routledge.

Lazarus, R. S., \& Folkman, S. (1984). Stress, appraisal, and coping. New York: Springer.

Lev, S., \& Koslowsky, M. (2008). Moderating the collective and self-efficacy relationship. Journal of Educational Administration, 47(4), 452-462.

Merton, R. K. (1957). Social theory and social structure. Glencoe: Free Press.

Protivnak, J. J., \& Foss, L. L. (2009). An exploration of themes that influence the counselor education doctoral student experience. Counselor Education and Supervision, 48(4), 239 - 256.

Rogers, C. R. (1959). Towards a theory of creativity. In H. H. Anderson (Ed.), Creativity and its cultivation. New York: Harper.

Terry, K. Y., DeMichiell, R., \& Williams, C. (2009). Mentoring tradeoffs: Breaking into the world of academe. Proceedings of Informing Science \& IT Education Conference (InSITE) 2009, 3 - 17. Retrieved from http://proceedings.informingscience.org/InSITE2009/InSITE09p003-015Terry632.pdf

Trochim, W. M., \& Donnelly, J. P. (2007). The research methods knowledge base (3rd ed.). Mason, OH: Thomson.

Ugrin, J. C., Odum, M. D., \& Pearson, J. M. (2008). Exploring the importance of mentoring for new scholars: A social exchange perspective. Journal of Information Systems Education, 19(3), 343 - 350.

Weber, M. (1970). From Max Weber: Essays in sociology. London: International Thomson Press and Kegan Paul.

Wood, R., \& Bandura, A. (1989). Social cognitive theory of organizational management. Academy of Management Review, 14(3), $361-384$.

\section{Biographies}

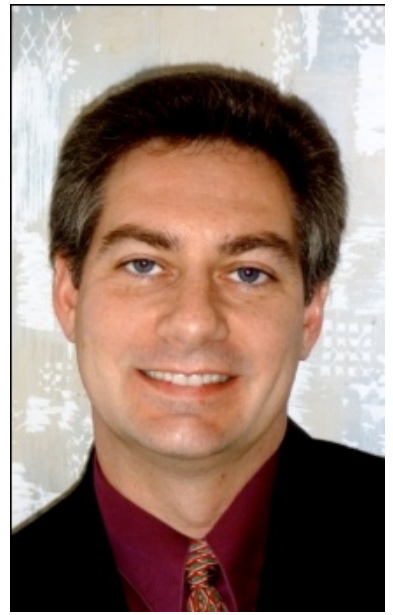

Robert E. Samuel, D.Sc., Adjunct Assistant Professor at Widener University has over 20 years of electri$\mathrm{cal} /$ computer/software/telecommunications engineering and information systems experience. He is an Accredited Advanced KAI Practitioner and is employed as an enterprise technology architect for a Fortune 100 international insurance firm. He holds a bachelor degree in Electrical Engineering and a graduate degree in Engineering from Widener University, a graduate degree in Information Science from Pennsylvania State University, and a Doctorate of Science in Information Systems and Communications from Robert Morris University. His research interests include trust in technology, cognitive diversity, ebusiness platforms, mobile computing, wireless networking, and software engineering. 


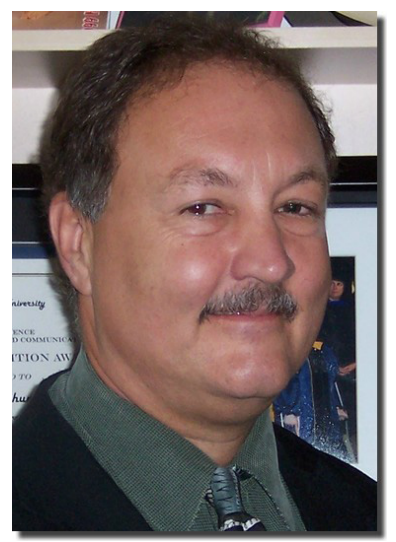

Frederick G. Kohun, Ph.D., Associate Provost and University Professor at Robert Morris University in Pittsburgh, Pennsylvania has more than 35 years experience as a professor, department head, and academic administrator in the economics, policy and information systems fields. He holds a bachelor degree in economics from Georgetown University, graduate degrees in economics and information science, from the University of Pittsburgh, and a Ph.D. in applied history in technology from Carnegie Mellon University. At Robert Morris University he led the design and implementation of eight technology based academic programs at the undergraduate and graduate level (including a doctoral program) as well as the attainment of ABET-CAC accreditation He is known both nationally and internationally from his numerous publications and presentations in health informatics, decision support, technological impact, and culture as well as his active involvement as an accreditation evaluator and team leader. In 2007, the International Association of Computer Information Systems named him the International Computer Educator of the Year. 